\title{
DEVELOPMENT OF ABRAHAM MODEL CORRELATIONS FOR SOLVATION CHARACTERISTICS OF SECONDARY AND BRANCHED ALCOHOLS
}

Laura M. Sprunger ${ }^{\mathrm{a}}$, Sai S. Achi ${ }^{\mathrm{a}}$, Racheal Pointer ${ }^{\mathrm{a}}$, William E. Acree, Jr. ${ }^{\mathrm{a}^{*}}$, Michael H. Abraham $^{\mathrm{b}}$

${ }^{a}$ Department of Chemistry, 1155 Union Circle Drive \#305070, University of North Texas, Denton, TX 76203-5017 (USA)

${ }^{\mathrm{b}}$ Department of Chemistry, University College London, 20 Gordon Street, London, WC1H 0AJ (UK)

\begin{abstract}
Data have been compiled from the published literature on the partition coefficients of solutes and vapors into the anhydrous secondary and branched alcohols (2-propanol, 2-butanol, 2-methyl-1-propanol, 2-methyl-2-propanol and 3-methyl-1-butanol) from both water and from the gas phase. The logarithms of the water-to-alcohol partition coefficients (log P) and gas-toalcohol partition coefficients $(\log \mathrm{K})$ were correlated with the Abraham solvation parameter model. The derived correlations described the observed $\log \mathrm{P}$ and $\log \mathrm{K}$ values to within average standard deviations of 0.14 and $0.13 \log$ units, respectively. The predictive abilities of the each correlation were assessed by dividing databases into a separate training set and test set.
\end{abstract}


KEY WORDS AND PHRASES: Partition Coefficients, Alcohol Solvents, Linear Free Energy

Correlations, Activity Coefficients, Solubilities, Henry’s Constants

* Corresponding author, Tel: +1 940565 3543; fax: +1 940565 4318; e-mail address: $\underline{\text { acree@unt.edu }}$ 


\section{Introduction}

Solubility of crystalline organic compounds in pure liquid solvents and in solvent mixtures plays a critical role in the synthesis and purification of commercial chemical products, such as dyes, pesticides, herbicides and pharmaceuticals. Synthetic methods often entail several steps that must be performed in series in order to prepare the desired product. For the more elaborate syntheses, one may have to isolate a chemical intermediate from the reaction media, purify the intermediate, and/or change the reaction solvent prior to adding the next set of chemical reactants. Predictive methods are available to facilitate solvent selection. Existing methods allow one to select a solvent capable of either dissolving the starting reactants, or precipitating a dissolved crystalline material from solution by addition of an anti-solvent, as would be the case involving purification by crystallization. Predictive methods are extremely useful in the design of synthetic strategies for preparing new chemical compounds having unmeasured physical and chemical properties.

The more successful of the published predictive methods are based on theoretical considerations regarding how a dissolved solute interacts with surrounding solvent molecules. The predictive method that we have been using is based on the Abraham solvation parameter model [1-6] for solute transfer between two condensed phases

$$
\log \mathrm{P}=\mathrm{c}+\mathrm{e} \cdot \mathbf{E}+\mathrm{s} \cdot \mathbf{S}+\mathrm{a} \cdot \mathbf{A}+\mathrm{b} \cdot \mathbf{B}+\mathrm{v} \cdot \mathbf{V}
$$

and for processes involving solute transfer from the gas phase to a condensed phase

$$
\log \mathrm{K}=\mathrm{c}+\mathrm{e} \cdot \mathbf{E}+\mathrm{s} \cdot \mathbf{S}+\mathrm{a} \cdot \mathbf{A}+\mathrm{b} \cdot \mathbf{B}+\mathrm{l} \cdot \mathbf{L}
$$


The dependent variables in Eqns. 1 and 2 are the logarithm of the solute's water-to-organic solvent partition coefficient, $\log \mathrm{P}$, and the logarithm of the solute's gas-to-organic solvent partition coefficient, $\log \mathrm{K}$. For solubility predictions, the model assumes that the partition between water and the organic solvent is given by the ratio of molar solubilities of the solute in the organic solvent, $\mathrm{C}_{\mathrm{S}}$ sat , and in water, $\mathrm{C}_{\mathrm{W}}{ }^{\text {sat }}$ (i.e., $\mathrm{P}=\mathrm{C}_{\mathrm{S}}{ }^{\text {sat }} / \mathrm{C}_{\mathrm{W}}{ }^{\text {sat }}$ ). The gas-to-organic solvent partition is similarly calculated as the molar solubility in the organic solvent divided by the solute gas phase concentration (i.e., $\mathrm{K}=\mathrm{C}_{\mathrm{S}}{ }^{\text {sat }} / \mathrm{C}_{\mathrm{G}}$ ), the latter value calculable from the solute vapor pressure above the solid at the solution temperature. The computation methodology is described in detail elsewhere. [3-6]

The independent variables in Eqns. 1 and 2 are solute descriptors as follows: $\mathbf{E}$ and $\mathbf{S}$ refer to the excess molar refraction and dipolarity/polarity descriptors of the solute, respectively, $\mathbf{A}$ and $\mathbf{B}$ are measures of the solute hydrogen-bond acidity and hydrogen-bond basicity, $\mathbf{V}$ is the McGowan volume of the solute and $\mathbf{L}$ is the logarithm of the solute gas phase dimensionless Ostwald partition coefficient into hexadecane at $298 \mathrm{~K}$. The first four descriptors can be regarded as measures of the tendency of the given solute to undergo various solute-solvent interactions. The latter two descriptors, $\mathbf{V}$ and $\mathbf{L}$, are both measures of solute size, and so will be measures of the solvent cavity term that will accommodate the dissolved solute. General dispersion interactions are also related to solute size, hence, both $\mathbf{V}$ and $\mathbf{L}$ will also describe the general solute-solvent interactions. The regression coefficients and constants (c, e, s, a, b, v and 1) are obtained by regression analysis of experimental data for a specific process (i.e., a given partitioning process or a given chromatographic stationary phase and mobile phase combination, etc.). In the case of partition coefficients, where two solvent phases are involved, the c, e, s, a, $\mathrm{b}, \mathrm{v}$ and $\mathrm{l}$ coefficients represent differences in the solvent phase properties. For any fully 
characterized system/process (those with calculated values for the equation coefficients), further values of $\log \mathrm{P}$ and $\log \mathrm{K}$ can be estimated with known values for the solute descriptors. This is the major advantage of using Eqns. 1 and 2 to correlate solute partitioning properties having environmental, pharmaceutical and chemical importance. To date we have reported equation coefficients for more than 50 different organic solvents.

The published Abraham model correlations that were used for the alcohol solvents in our recent solubility studies $[7,8]$ were derived more than ten years ago. These earlier correlations were based on the limited experimental data that was available at the time. It is important to periodically update the earlier correlations as additional experimental data becomes available to ensure that the predictive expressions span as wide a range of descriptor space as possible. Dragos and coworkers [9] recently noted that quantitative structure property relationship (qsar) and linear free energy relationship (lfer) models are fitted to minimize discrepancies between calculated and observed property values within a training set of molecules. The derived correlations are known to depend on the choice of molecules in the training set. The authors went on to state that no matter how large the training set is, it may never represent a significant sample of chemical structure space. The predictive area of chemical space for the Abraham model is defined not by chemical structures, but rather by the range of numerical values covered by the solute descriptors of the compounds contained in the database used to derive the respective correlation models. In this regard, we just updated the Abraham model correlations for the linear alcohols (methanol through 1-octanol, and 1-decanol). [10,11] The updated $\log \mathrm{P}$ and $\log \mathrm{K}$ partition coefficient correlations pertain to solutes dissolved in the anhydrous (dry) linear alcohol solvents. The revised correlations were based on much larger databases, and 
included a much larger number of the more acidic solutes (such as crystalline benzoic acid derivatives) and a much greater number of the more nonvolatile solutes.

In the present study we have reanalyzed the available experimental $\log \mathrm{P}$ and $\log \mathrm{K}$ partition coefficient data for solutes dissolved in anhydrous 2-propanol, 2-butanol, 2-methyl-1propanol, 2-methyl-2-propanol and 3-methyl-1-propanol. Equation coefficients for these five anhydrous alcohol solvents were reported several years ago in solubility studies concerning the calculation of solute descriptors of select crystalline organic compounds. The values that were reported previously were based on much smaller data bases. The databases used to derive the earlier correlations were never published, and the statistical information for the earlier correlations was never reported. The Abraham model $\log \mathrm{P}$ and $\log \mathrm{K}$ correlations that we present here for the five anhydrous secondary and branched alcohols are based on significantly larger databases containing compounds of greater chemical diversity, molecular size and hydrogen-bonding characteristics. The larger databases allow us to validate the derived correlation models through training set and test set analyses.

\section{Data Sets and Computation Methodology}

Most of the experimental data that we were able to retrieve from the published literature [3-7, 12-174] pertained either to the Raoult's law infinite dilution activity coefficient, $\gamma_{\text {solute }}$, Henry's law constants, $\mathrm{K}_{\text {Henry, }}$ or solubilities for solutes dissolved in anhydrous 2-propanol, 2butanol, 2-methyl-1-propanol, 2-methyl-2-propanol and 3-methyl-1-butanol. In order to apply the Abraham model the infinite dilution activity coefficients and Henry's law constants needed to be converted to $\log \mathrm{K}$ values through Eqns. 3 and 4 


$$
\begin{aligned}
& \log K=\log \left(\frac{R T}{\gamma_{\text {solute }}{ }^{\infty} V P_{\text {solute }}{ }^{o} V_{\text {solvent }}}\right) \\
& \log K=\log \left(\frac{R T}{K_{\text {Henry }} V_{\text {solvent }}}\right) \\
& \log P=\log K-\log K_{w}
\end{aligned}
$$

and to $\log \mathrm{P}$ values for partition from water to the anhydrous 1-alcohols through Eqn. 5. In equations 3 and 4, $\mathrm{R}$ is the universal gas constant, $\mathrm{T}$ is the system temperature, $\mathrm{VP}_{\text {solute }}{ }^{\mathrm{o}}$ is the vapor pressure of the solute at $\mathrm{T}$, and $\mathrm{V}_{\text {solvent }}$ is the molar volume of the solvent. The calculation of $\log$ P requires knowledge of the solute's gas phase partition coefficient into water, $\mathrm{K}_{\mathrm{w}}$, which is available for most of the solutes being studied. The experimental $\log \mathrm{K}$ and $\log \mathrm{P}$ values at 298.15 for anhydrous 2-propanol, 2-butanol, 2-methyl-1-propanol, 2-methyl-2-propanol and 3methyl-1-butanol are listed in Tables S1-S5 (Supporting information). As an informational note, the calculated $\log \mathrm{P}$ values for the five anhydrous alcohols refer to a hypothetical partition coefficient. Even though hypothetical, these $\log \mathrm{P}$ correlations are still quite useful in that predicted $\log \mathrm{P}$ values can be used to estimate the solute's infinite dilution activity coefficient or molar solubility in the anhydrous alcohol solvent for those solutes for which the solute descriptors are known.

Our experimental databases also contain measured solubility data for several crystalline solutes dissolved in both the anhydrous 1-alcohols and in water. The solubility data were taken largely from our previously published solubility studies. At the time that our solubility studies were performed we included solvents for which we planned to update and to derive correlation 
equations in the future. In the case of crystalline solutes, the partition coefficient between water and the anhydrous organic solvent is calculated as a solubility ratio

$$
\mathrm{P}=\mathrm{C}_{\mathrm{S}} / \mathrm{C}_{\mathrm{W}}
$$

of the solute's molar solubilities in the organic solvent, $\mathrm{C}_{\mathrm{S}}$, and in water, $\mathrm{C}_{\mathrm{W}}$. Molar solubilities can also be used to calculate $\log \mathrm{K}$ values, provided that the equilibrium vapor pressure of the solute above crystalline solute, $\mathrm{P}_{\text {solute }}{ }^{\circ}$, at $298.15 \mathrm{~K}$ is also available. $\mathrm{P}_{\text {solute }}{ }^{\circ}$ can be transformed into the gas phase concentration, $\mathrm{C}_{\mathrm{G}}$, and the gas-to-water and gas-to-organic solvent partitions, $\mathrm{K}_{\mathrm{W}}$ and $\mathrm{K}$, can be obtained through the following equations

$$
\mathrm{K}_{\mathrm{W}}=\mathrm{C}_{\mathrm{W}} / \mathrm{C}_{\mathrm{G}} \quad \text { or } \quad \mathrm{K}=\mathrm{C}_{\mathrm{S}} / \mathrm{C}_{\mathrm{G}}
$$

The vapor pressure and aqueous solubility data needed for these calculations are reported in our previous publications.

As noted in an earlier publication [3], three conditions must be met to calculate partition coefficients from solubility data. The conditions are as follows: (1) the same solid phase must be in equilibrium with the saturated solutions in the solvent and in water (in practice this means that there should be no solvate or hydrate formation); (ii) the secondary medium activity coefficient of the solid in the saturated solutions must be unity (or near unity); and (iii) for the solutes that are ionized in aqueous solution, $\mathrm{C}_{\mathrm{W}}$, must refer to the solubility of the neutral form. The second condition would restrict the method to those solutes that are sparingly soluble in water and in the organic solvent. Past applications $[3,8,69,82,92]$ have show that the Abraham model does accurately describe the solubility of several fairly soluble solutes. For example, Eqns. 2 and 3 described the molar solubility of benzil in 24 organic solvents to within overall standard 
deviations of 0.124 and $0.109 \log$ units, respectively. [69] Standard deviations for acetylsalicylic acid dissolved in 13 alcohols, 4 ethers and ethyl acetate were 0.123 and 0.138 log units. [92] Flanagan and coworkers [82] further showed that Eqs. 1 and 2 of the Abraham model predicted the experimental solubilities of 1,2,4,5-tetramethylbenzene in 25 different solvents to within an overall standard deviation of $0.15 \log$ units using numerical values of the solute descriptors that had been previously calculated from infinite dilution partition coefficient and chromatographic retention data. Benzil, acetylsalicylic acid and 1,2,4,5-tetramethylbenzene exhibited solubilities exceeding 1 Molar in many of the organic solvents.

Molecular descriptors for all of the compounds considered in the present study are also tabulated in Tables S1 - S5. The tabulated values came from our solute descriptor database, and were obtained using various types of experimental data, including water-to-solvent partitions, gas-to-solvent partitions, solubility and chromatographic data. [2,4]

\section{Results and Discussion}

We have assembled in Table S1 (Supporting Information) $148 \log$ P values and $146 \log$ $\mathrm{K}$ values for solutes dissolved in anhydrous 2-propanol covering a reasonably wide range of compound type and descriptor values. Our previously derived 2-propanol correlations were based on $96 \log \mathrm{P}$ and $96 \log \mathrm{K}$ values, and did not contain the larger solutes like rutin $(\mathbf{V}=$ 3.965) and podophyllotoxin $(\mathbf{V}=2.834)$, which have not only large $\mathbf{V}$ solute descriptors, but large $\mathbf{E}, \mathbf{S}$, and $\mathbf{B}$ values as well. As noted above in using predictive equations it is important to 
stay within the chemical space defined by the range of solute descriptors covered. Analysis of the experimental data yielded the following correlation equations

$\log \mathrm{P}=0.099(0.027)+0.343(0.041) \mathbf{E}-1.049(0.059) \mathbf{S}+0.406(0.053) \mathbf{A}-3.827(0.067) \mathbf{B}$

$$
\begin{aligned}
& +4.033(0.028) \mathrm{V} \\
& \left(\mathrm{N}=148, \mathrm{SD}=0.159, \mathrm{R}^{2}=0.994, \mathrm{~F}=4929\right)
\end{aligned}
$$

and

$$
\begin{aligned}
\log K= & -0.048(0.017)-0.324(0.035) \mathbf{E}+0.713(0.046) \mathbf{S}+4.036(0.041) \mathbf{A}+1.055(0.054) \mathbf{B} \\
& +0.884(0.006) \mathbf{L} \\
& \left(\mathrm{N}=146, \mathrm{SD}=0.122, \mathrm{R}^{2}=0.999, \mathrm{~F}=40,021\right)
\end{aligned}
$$

All regression analyses were performed using SPSS statistical software. The standard errors in the calculated coefficients are given in parenthesis. Here and elsewhere, $\mathrm{N}$ corresponds to the number of solutes, $\mathrm{R}$ denotes the correlation coefficient, SD is the standard deviation and F corresponds to the Fisher F-statistic. The statistics of both correlations are quite good as evidenced by the near unity values of the squared correlation coefficients and by the small standard deviations of $\mathrm{SD}=0.159$ and $\mathrm{SD}=0.122 \log$ units. See Figures 1 and 2 for plots of the calculated $\log \mathrm{P}$ and $\log \mathrm{K}$ values based on Eqns. 8 and 9 against observed data. The experimental $\log \mathrm{P}$ and $\log \mathrm{K}$ values cover ranges of about 16.1 and $36.1 \log$ units, respectively.

In order to assess the predictive ability of Eqns. 8 and 9 we divided the data points into a training set and a test set by allowing the SPSS software to randomly select half of the experimental data points. The selected data points became the training sets and the remaining 
compounds that were left served as the test sets. Analysis of the experimental data in the $\log \mathrm{P}$ and $\log \mathrm{K}$ training sets gave

$\log \mathrm{P}=0.095(0.044)+0.338(0.071) \mathbf{E}-1.098(0.103) \mathbf{S}+0.454(0.099) \mathbf{A}-3.811(0.135) \mathbf{B}$

$$
\begin{aligned}
& +4.049(0.048) \mathrm{V} \\
& \left(\mathrm{N}=74, \mathrm{SD}=0.161, \mathrm{R}^{2}=0.992, \mathrm{~F}=1838\right)
\end{aligned}
$$

and

$$
\begin{aligned}
\log K= & -0.037(0.022)-0.366(0.045) \mathbf{E}+0.699(0.056) \mathbf{S}+4.092(0.062) \mathbf{A}+0.995(0.070) \mathbf{B} \\
& +0.898(0.008) \mathbf{L} \\
& \left(\mathrm{N}=73, \mathrm{SD}=0.109, \mathrm{R}^{2}=1.000, \mathrm{~F}=29,823\right)
\end{aligned}
$$

There is very little difference in the equation coefficients for the full dataset and the training dataset correlations, thus showing that both training sets of compounds are representative samples of the total $\log \mathrm{P}$ and $\log \mathrm{K}$ data sets. The derived training set equations were then used to predict the respective partition coefficients for the compounds in the test sets. For the predicted and experimental values, we found $\mathrm{SD}=0.161$ (Eqn. 10) and SD =0.136 (Eqn. 11), $\mathrm{AAE}$ (average absolute error) $=0.123($ Eqn. 10) and AAE $=0.112$ (Eqn. 11), and AE (average error $)=0.025($ Eqn. 10) and $\mathrm{AE}=-0.054($ Eqn. 11). There is therefore very little bias in using Eqns. 10 and 11 with AE equal to 0.025 and $-0.054 \log$ units. The training and test set analyses were performed two more times with similar results.

We have assembled in Table S2 (Supporting Information) $97 \log \mathrm{P}$ values and $95 \log \mathrm{K}$ values for solutes dissolved in 2-butanol covering a reasonably wide range of compound type 
and descriptor values. Analysis of the experimental data yielded the following correlation equations

$\log \mathbf{P}=0.127(0.029)+0.253(0.046) \mathbf{E}-0.976(0.060) \mathbf{S}+0.158(0.056) \mathbf{A}-3.882(0.079) \mathbf{B}$

$$
\begin{aligned}
& +4.114(0.039) \mathrm{V} \\
& \left(\mathrm{N}=97, \mathrm{SD}=0.129, \mathrm{R}^{2}=0.994, \mathrm{~F}=3232\right)
\end{aligned}
$$

and

$$
\begin{aligned}
\log \mathrm{K} & =-0.034(0.025)-0.387(0.054) \mathbf{E}+0.719(0.069) \mathbf{S}+3.736(0.059) \mathbf{A}+1.088(0.087) \mathbf{B} \\
& +0.905(0.011) \mathbf{L} \\
& \left(\mathrm{N}=95, \mathrm{SD}=0.138, \mathrm{R}^{2}=0.999, \mathrm{~F}=14696\right)
\end{aligned}
$$

Both correlations provide a reasonably accurate mathematical description of the experimental water-to-anhydrous 2-butanol partition coefficient data (Eqn. 12) and gas-to-anhydrous 2-butanol partition coefficient data (Eqn. 13) for experimental values that cover ranges of about 14.5 and $15.8 \log$ units, respectively.

We have assessed the predictive ability of Eqns. 12 and 13 by dividing the $97 \log \mathrm{P}$ and $95 \log \mathrm{K}$ data points into training sets and test sets as before. Analysis of the experimental data gave

$\log \mathbf{P}=0.099(0.047)+0.242(0.067) \mathbf{E}-0.954(0.092) \mathbf{S}+0.129(0.083) \mathbf{A}-3.966(0.165) \mathbf{B}$

$$
\begin{aligned}
& +4.150(0.047) \mathbf{V} \\
& \left(\mathrm{N}=49, \mathrm{SD}=0.136, \mathrm{R}^{2}=0.995, \mathrm{~F}=1940\right)
\end{aligned}
$$


and

$$
\begin{aligned}
\log K= & -0.055(0.030)-0.247(0.104) \mathbf{E}+0.760(0.123) \mathbf{S}+3.862(0.101) \mathbf{A}+0.903(0.166) \mathbf{B} \\
& +0.880(0.023) \mathbf{L} \\
& \left(\mathrm{N}=48, \mathrm{SD}=0.126, \mathrm{R}^{2}=0.999, \mathrm{~F}=8572\right)
\end{aligned}
$$

There is very little difference in the equation coefficients for the full dataset and the training dataset correlations, thus showing that both training sets of compounds are representative samples of the total $\log \mathrm{P}$ and $\log \mathrm{K}$ data sets. The derived training set equations were then used to predict the respective partition coefficients for the compounds in the test sets. For the predicted and experimental values, we found $\mathrm{SD}=0.125$ (Eqn. 14) and $\mathrm{SD}=0.180$ (Eqn. 15), AAE (average absolute error) $=0.094$ (Eqn. 14) and AAE $=0.131$ (Eqn. 15), and AE (average error $)=0.035($ Eqn. 14) and $\mathrm{AE}=0.048($ Eqn. 15). There is therefore very little bias in using Eqns. 14 and 15 with AE equal to 0.057 and 0.048 log units. The training and test set analyses were performed two more times with similar results.

The experimental $\log \mathrm{P}$ and $\log \mathrm{K}$ values for 2-methyl-1-propanol, 2-methyl-2-propanol and 3-methyl-1-butanol in Tables S3 - S5 (Supporting Information) were analyzed in similar fashion. To conserve journal space we have tabulated the calculated equation coefficients and the associated statistical information in Tables 1 and 2. Listed below the equation coefficients are the respective standard errors. For convenience we have also included in Tables 1 and 2 the equation coefficients for 2-propanol and 2-butanol reported above. Examination of the statistical information reveals that the Abraham solvation parameter model does provide very accurate mathematical descriptions for the observed gas-to-alcohol and water-to-alcohol partition 
coefficient data for solutes dissolved in the eight anhydrous alcohol solvents studied here. (See Figures S1 - S6 of the Supporting Information for plots of the observed data versus calculated values based on the Abraham model.) Each derived correlation was validated through training set and test set analyses. Full details of the validation results are given in Tables S6 - S8 (Supporting information).

The coefficients in the Abraham model are not just fitting coefficients but can be interpreted in terms of chemical interactions. The $\log \mathrm{K}$ correlations are easier to interpret because only one solvent phase is involved and the coefficients represent differences between the gas and solvent phase. The coefficients in the log $\mathrm{P}$ equations refer to differences between the water and anhydrous alcohols. For the $\log \mathrm{K}$ correlation the e-coefficient gives the ability of the alcohol to interact with $\sigma$ - and $\pi$-electrons, the s-coefficient gives the hydrogen-bond basicity (because an acidic solute will interact with a basic solvent), the b-coefficient gives the hydrogenbond acidity (because a basic solute will interact with an acidic solvent), and the l-coefficient will reflect an endoergic cavity effect dependent upon solute size. The five alcohol solvents that have been studied here do not belong to a single class. The hydroxyl group is attached to a secondary carbon atom in three of the alcohols (2-propanol, 2-butanol and 2-methyl-1-propanol), to a primary carbon atom in one alcohol (3-methyl-1-butanol), and to a tertiary carbon atom in the case of 2-methyl-2-propanol. Comparisons are further complicated by the presence of a methyl-substituent in different locations relative to the hydroxyl group.

To facilitate comparisons we have listed in Table 2 the revised/updated equation coefficients for 1-propanol and 1-butanol. [11] Examination of the numerical entries reveals that the e-coefficient of 2-propanol and 2-butanol (-0.324 and -0.387) are more negative than the e- 
coefficients of the corresponding linear alcohols (-0.246 for 1-propanol and -0.285 for 1 butanol). The s-coefficients are slightly larger in the case of linear alcohols, suggesting slightly larger dipolarity/polarity interactions with dissolved solutes. Of the five alcohols studied, 2methyl-2-propanol has the smallest b-coefficient. This is to be expected as the presence of three neighboring methyl groups should sterically hinder the alcohol's ability to act as a hydrogenbond donor. Give the few number of alcohols studied, the relatively small differences in the coefficients between alcohols, and the standard errors in each respective coefficient, it is difficult to make a more detailed comparison at the present time.

The present study shows that the correlations derived from the Abraham solvation parameter model provide reasonably accurate mathematical descriptions of solute transfer from both water and from the gas phase into the secondary and branched alcohols. Future studies will explore the possibility of correlating the linear alcohols (methanol through 1-decanol) and the secondary and branched alcohols with a single Abraham model correlation. The derived correlations presented here do pertain to 298.15 K. Many manufacturing and separation processes take place at higher temperatures, and there is a growing need to determine partition properties into organic solvents at other temperatures. In this regard, we have recently published enthalpy of solvation correlations, $\Delta \mathrm{H}_{\text {solv }}$, for organic gases and gaseous solutes into water [175] and 2-methyl-2-propanol [176]. The $\Delta \mathrm{H}_{\text {solv }}$ correlations will allow one to extrapolate the predicted $\log \mathrm{P}$ (wet and dry) and $\log \mathrm{K}$ (wet and dry) for 2-methyl-2-propanol based on Eqns. 1 and 2 (coefficients in Tables 1 and 2) to other temperatures not too far removed from $298.15 \mathrm{~K}$.

\section{Acknowledgements}


Racheal Pointer thanks the National Science Foundation for support received under NSF-REU grant (CHE-0648843). Sai Achi thanks the University of North Texas's Texas Academy of Math and Science (TAMS) program for a summer research award. 
References

1. M. H. Abraham, Chem. Soc. Reviews 22 (1993) 73-83.

2. M. H. Abraham, A. Ibrahim, A. M. Zissimos, J. Chromatogr. A 1037 (2004) 29-47.

3. M. H. Abraham, C. E. Green, W. E. Acree, Jr., C. E. Hernandez, L. E. Roy, J. Chem. Soc., Perkin Trans. 2 (1998) 2677-2682.

4. C. E. Green, M. H. Abraham, W. E. Acree, Jr., K. M. De Fina, T. L. Sharp, Pest Manage. Sci. 56 (2000) 1043-1053.

5. W. E. Acree, Jr., M. H. Abraham, Fluid Phase Equilibr. 201 (2002) 245-258.

6. W. E. Acree, Jr., M. H. Abraham, Can. J. Chem. 79 (2001) 1466-1476.

7. B. H. Blake-Taylor, V. H. Deleon, W. E. Acree, Jr., M. H. Abraham, Phys. Chem. Liq. 45 (2007) 389-398.

8. L. M. Sprunger, A. Proctor, W. E. Acree, Jr., M. H. Abraham, Phys. Chem. Liq. 46 (2008) 574-585.

9. H. Dragos, M. Gilles, V. Alexandre, J. Chem. Inf. Model. 49 (2009) 1762-1776.

10. Abraham, Michael H.; Acree, William E., Jr. J. Phys. Org. Chem. 21 (2008) 823-832.

11. L. M. Sprunger, S. S. Achi, R. Pointer, B. H. Blake-Taylor, W. E. Acree, Jr., M. H. Abraham, Fluid Phase Equilibr., in press.

12. V. N. Prorokov, V. V. Dolotov, G. A. Krestov, Zh. Fiz. Khim. 58 (1984) 1888-1890.

13. M. H. Abraham, J. Amer. Chem. Soc. 104 (1982) 2085-2094.

14. J. Tokunaga, J. Chem. Eng. Data 20 (1975) 41-46.

15. H. Yamamoto, K. Ichikawa, J. Tokunaga, J. Chem. Eng. Data 39 (1994) 155-157.

16. P. S. Puri, J. A. Ruether, Can. J. Chem. Eng. 52 (1974) 636-640. 
17. P. Vrbka, V. Dohnal, L. M. Trego, M. Costas, Fluid Phase Equilibr. 137 (1997) 133-140.

18. D. I. Eikens, Ph. D. Dissertation, University of Minnesota, 1993.

19. C. E. Loeffler, J. j. McKetta, Jr., J. Chem. Eng. Data 11 (1966) 431-433.

20. E. Sada, S. Kito, Y. Ito, Ind. Eng. Chem. Fundam. 14 (1975) 232-237.

21. D. M. Trampe, C. A. Eckert, J. Chem. Eng. Data 35 (1990) 156-162.

22. J. H. Park, A. Hussam, P. Couasnon, D. Fritz, P. W. Carr, Anal. Chem. 59 (1987) 19701976.

23. K. C. Sing, K. C. Kalra, S. Maken, V. Gupta, Fluid Phase Equilibr. 123 (1996) 271-281.

24. P. Oracz, Int. DATA Ser., Sel. Data Mix. (1989) 271-273.

25. R. Garriga, F. Sanchez, P. Perez, M. Gracia, Fluid Phase Equilibr. 124 (1996) 123-134.

26. R. Hasse, W. Tillmann, Z. Phys. Chem., 192 (1995) 121-131.

27. P. Oracz, Int. DATA Ser., Sel. Data Mix. (1989) 268-270.

28. A. Sahgal, H. M. La, W. Hayduk, Can. J. Chem. Eng. 56 (1978) 354-357.

29. Y. Miyano, J. Chem. Eng. Data 49 (2004) 368-371.

30. Miyano, Yoshimori; Kobashi, Takahiro; Shinjo, Hiroshi; Kumada, Shinya; Watanabe, Yusuke; Niya, Wataru; Tateishi, Yoko. Journal of Chemical Thermodynamics (2006), 38(6), 724-731.

31. J. Gmehling, J. Menke, M. Schiller, Activity Coefficients at Infinite Dilution; Chemical Data Series, Volume IX, Part 3, DECHMA, Frankfurt/Main, Germany, 1994.

32. J. Gmehling, U. Onken, W. Arlt, Vapor-Liquid Equilibrium Data Collection, Chemical Data Series, Volume I, parts 2b-d, DECHEMA, Frankfurt/Main, Germany, 1984.

33. K. A. Pividal, A. Birtigh, S. I. Sandler, J. Chem. Eng. Data 37 (1992) 484-487.

34. A. Heintz, E. Dolch, R. N. Liechtenthaler, Fluid Phase Equilibr. 27 (1986) 61-79. 
35. J. O. Triday, J. Chem. Eng. Data 28 (1983) 307-310.

36. J. A. Salas, E. L. Arancibia, M. Katz, Can. J. Chem. 75 (1997) 207-211.

37. S. Warycha, Int. DATA Ser., Sel. Data Mix. (1994) 85-87.

38. R. Garriga, F. Sanchez, P. Perez, M. Gracia, Fluid Phase Equilibr. 138 (1997) 131-144.

39. S. M. Bardavid, G. C. Pedrosa, M. Katz, Latin Amer. Appl. Res. 22 (1992) 225-229.

40. J. A. Salas, E. L. Arancibia, M. Katz, Fluid Phase Equilibr. 152 (1998) 255-263.

41. M. H. Abraham, P. L. Grellier, A. Nasehzadeh, R. A. C. Walker, J. Chem. Soc., Perkin Trans. II (1988) 1717-1724.

42. R. Garriga, F. Sanchez, P. Perez, M. Gracia, J. Chem. Thermodyn. 27 (1995) 887-895.

43. K. W. Chun, J. C. Drummond, R. R. Davison, J. Chem. Eng. Data 19 (1974) 142-144.

44. O. Y. Guzechak, V. N. Sarancha, I. M. Romanyuk, O. M. Yavorskaya, G. P. Churik, Zhur. Prikl. Khim. 57 (1984) 1798-1801.

45. P. Oracz, Int. DATA Ser., Sel. Data Mix. (1989) 277-279.

46. P. Oracz, Int. DATA Ser., Sel. Data Mix. (1989) 279-282.

47. G. C. Benson, Int. DATA Ser., Sel. Data Mix. (1985) 231-233.

48. C. W. Hoerr, H. J. Harwood, A. W. Ralston, J. Org. Chem. 9 (1944) 267-280.

49. U. Domanska, A. M. Szafranski, Int. DATA Ser., Sel. Data Mix. (1987) 279.

50. U. Domanska, A. M. Szafranski, Int. DATA Ser., Sel. Data Mix. (1987) 282.

51. U. Domanska, A. M. Szafranski, Int. DATA Ser., Sel. Data Mix. (1987) 285.

52. M. H. Abraham, P. L. Grellier, R. A. McGill, J. Chem. Soc., Perkin Trans. 2 (1988) 339345. 
53. B. S. Reddy, A. R. Prasad, K. V. Rao, Recent Trends Biotechnol., Proc. Ninth Natl. Conv. Chem. Eng. Int. Symp. "Importance Biotechnol. Coming Decades" (1993), 203206.

54. F. Comelli and R. Francesconi, J. Chem. Eng. Data 41 (1996) 1392-1396.

55. R. Ruelle, U. W. Kesselring, J. Mol. Liq. 67 (1995) 81-94.

56. L. Dang, W. Du, S. Black, H. Wei, J. Chem. Eng. Data (2009) ACS ASAP.

57. K. R. Hoover, W. E. Acree, Jr., M. H. Abraham, Phys. Chem. Liq. 44 (2006) 367-376.

58. K. R. Hoover, W. E. Acree, Jr., M. H. Abraham, J. Solution Chem. 34 (2005) 1121-1133.

59. C. R. Daniels, A. K. Charlton, R. M. Wold, R. J. Moreno, W. E. Acree, Jr., M. H. Abraham, Phys. Chem. Liq. (2004), 42 (2004) 633-641.

60. K. R. Hoover, D. M. Stovall, E. Pustejovsky, R. Coaxum, K. Pop, W. E. Acree, Jr., M. H. Abraham, Can. J. Chem. 82 (2004) 1353-1360.

61. K. R. Hoover, R. Coaxum, E. Pustejovsky, W. E. Acree, Jr., M. H. Abraham, Phys. Chem. Liq. 42 (2004) 457-466.

62. C. R. Daniels, A. K. Charlton, R. M. Wold, E. Pustejovsky, A. N. Furman, A. C. Bilbrey, J. N. Love, J. A. Garza, W. E. Acree, Jr., M. H. Abraham, Phys. Chem. Liq. 42 (2004) 481-491.

63. K. R. Hoover, R. Coaxum, E. Pustejovsky, D. M. Stovall, W. E. Acree, Jr., M. H. Abraham, Phys. Chem. Liq. 42 (2004) 339-347.

64. R. Coaxum, K. R. Hoover, E. Pustejovsky, D. M. Stovall, W. E. Acree, Jr., M. H. Abraham, Phys. Chem. Liq. 42 (2004) 313-322.

65. C. R. Daniels, A. K. Charlton, W. E. Acree, Jr., M. H. Abraham, Phys. Chem. Liq. 42 (2004) 305-312. 
66. C. I. Monarrez, D. M. Stovall, J. H. Woo, P. Taylor, W. E. Acree, Jr., Phys. Chem. Liq. 41 (2003) 73-80.

67. C. I. Monarrez, D. M. Stovall, J. H. Woo, P. Taylor, W. E. Acree, Jr., Phys. Chem. Liq. 40 (2002) 703-714.

68. C. I. Monarrez, W. E. Acree, Jr., M. H. Abraham, Phys. Chem. Liq. 40 (2002) 581-591.

69. W. E. Acree, Jr., M. H. Abraham, J. Solution Chem. 31 (2002) 293-303.

70. K. M. De Fina, C. Ezell, W. E. Acree, Jr. Phys. Chem. Liquids 39 (2001), 699-710.

71. K. M. De Fina, T. L. Sharp, W. E. Acree, Jr., Can. J. Chem. 77 (1999) 1537-1541.

72. C. E. Hernandez, W. E. Acree, Jr., Can. J. Chem. 76 (1998) 1312-1316.

73. K. A. Fletcher, M. E. R. McHale, K. S. Coym, W. E. Acree, Jr., Can. J. Chem. 75 (1997) 258-261.

74. W. V. Wilding, N. F. Giles, L. C. Wilson, J. Chem. Eng. Data 41 (1996) 1239-1251

75. K. M. De Fina, T. L. Sharp, M. A. Spurgin, I. Chuca, W. E. Acree, Jr., C. E. Green, M. H. Abraham, Can. J. Chem. 78 (2000) 184-190.

76. K. M. De Fina, T. L. Sharp, I. Chuca, M. A. Spurgin, W. E. Acree, Jr., C. E. Green, M. H. Abraham, Phys. Chem. Liq. 40 (2002) 255-268.

77. A. A. Penlin, L. G. Vasil'neva, S. O. Karabaev, O. M. Susareva, Russ. J. Phys. Chem. 64 (1990) 935-938.

78. D. M. Stovall, C. Givens, S. Keown, K. R. Hoover, R. Barnes, C. Harris, J. Lozano, M. Nguyen, E. Rodriguez, W. E. Acree, Jr., M. H. Abraham, Phys. Chem. Liq. 43 (2005), 351-360.

79. D. M. Stovall, W. E. Acree, Jr., M. H. Abraham, Fluid Phase Equilibr. 232 (2005) 113121. 
80. K. B. Flanagan, K. R. Hoover, O. Garza, A. Hizon, T. Soto, N. Villegas, W. E. Acree, Jr., M. H. Abraham, Phys. Chem. Liquids 44 (2006) 377-386.

81. A. A. Sunier, J. Phys. Chem. 34 (1930) 2582-2597.

82. K. B. Flanagan, K. R. Hoover, W. E. Acree, Jr., M. H. Abraham, Phys. Chem. Liq. 44 (2006) 173-182.

83. C. R. Daniels, A. K. Charlton, R. M. Wold, W. E. Acree, Jr., M. H. Abraham, Can. J. Chem. 81 (2003) 1492-1501.

84. K. R. Hoover, K. Pop, W. E. Acree, Jr., M. H. Abraham, South African J. Chem. 58 (2005) 25-29.

85. A. K. Charlton, C. R. Daniels, R. M. Wold, E. Pustejovsky, W. E. Acree, Jr., M. H. Abraham, J. Mol. Liq. 116 (2005) 19-28.

86. K. M. De Fina, T. T. Van, K. A. Fletcher, W. E. Acree, Jr., Can. J. Chem. 78 (2000) 449453.

87. K. M. De Fina, T. L. Sharp, W. E. Acree, Jr., Can. J. Chem. 77 (1999) 1589-1593.

88. A. Martin, P. L. Wu, A. Beerbower, J. Pharm. Sci. 73 (1984) 188-194.

89. S. Gracin, A. C. Rasmuson, J. Chem. Eng. Data 47 (2002) 1379-1383.

90. S. Warycha, Int. DATA Ser., Sel. Data Mix. (1994) 108-110.

91. R. A. Granberg, A. C. Rasmuson, J. Chem. Eng. Data 44 (1999) 1391-1395.

92. A. K. Charlton, C. R. Daniels, W. E. Acree, Jr., M. H. Abraham, J. Solution Chem. 32 (2003) 1087-1102.

93. W. V. Wilding, Int. DATA Ser., Sel. Data Mix., Ser. A (2003) 175.

94. H. Brusset, P. Delvalle, M. Philoche-Levisalles, L. Demanee, Bull. Soc. Chim. France (1968) 3113-3120. 
95. L. R. Greene, A. C. Blackburn, J. M. Miller, J. Pharm. Biomed. Anal. 39 (2005) 344-347. 96. S. M. Leschev, N. P. Novik, J. Struct. Chem. 40 (1999) 424-427.

97. A. N. Gaivoronskii, V. A. Granzhan, Russ. J. Appl. Chem. 78 (2005) 404-408.

98. M. H. Abraham, J. Gil-Lostes, W. E. Acree, Jr., J. E. Cometto-Muniz, W. S. Cain, J. Environ. Monit. 10 (2008) 435-442.

99. B. Long, Y. Wang, R. Zhang, J. Xu, J. Chem. Eng. Data 54 (2009) 1764-1766.

100. A. Beerbower, P. L. Wu, A. Martin, J. Pharm. Sci. 73 (1984) 179-188.

101. J. Zi, B. Peng, W. Yan, Fluid Phase Equilibr. 261 (2007) 111-114.

102. D. Wei, Y. Pei, J. Chem. Eng. Data 53 (2008) 2710-2711.

103. P. J. Richardson, D. F. McCafferty, A. D. Woolfson, Int. J. Pharm. 79 (1992) 189-198.

104. B. Peng, J. Zi, W. Yan, J. Chem. Eng. Data 51 (2006) 2038-2040.

105. J. Gao, Z. Wang, D. Xu, R. Zhang, J. Chem. Eng. Data 52 (2007) 189-191.

106. L.-S. Gan, Z.-Z. Wang, C.-X. Zhou, J. Chem. Eng. Data 54 (2009) 160-161.

107. D. Wei, Y. Pei, F. Yan, J. Chem. Eng. Data 54 (2009) 142-143.

108. Q.-S. Zi, Z. Li, S. Wang, J. Chem. Eng. Data 53 (2008) 286-287.

109. D. M. Stovall, C. Givens, S. Keown, K. R. Hoover, E. Rodriguez, W. E. Acree, Jr., M. H. Abraham, Phys. Chem. Liq. 43 (2005) 261-268.

110. A. Shalmashi, A. Eliassi, J. Chem. Eng. Data 53 (2008) 1332-1334.

111. J. Pardo, M. C. Lpez, J. A. Mayoral, F. M. Royo, J. S. Urieta, Fluid Phase Equilibr. 134 (1997) 133-140.

112. Q. Yu, S. Black and H. Wei, J. Chem. Eng. Data, 2009, in press.

113. Y. Miyano, J. Chem. Eng. Data 49 (2004) 1285-1289.

114. S. Thomas, V. R. Bhethanbotla, S. W. Campbell, J. Chem. Eng. Data 36 (1991) 374-378. 
115. R. Garriga, F. Sanchez, P. Perez, M. Gracia, J. Chem. Eng. Data 42 (1997) 78-83.

116. M.-C. Haulait-Pirson, G. Huys, E. Vanstraelen, Ind. Eng. Chem. Res. 26 (1987) 447-452.

117. H. T. French, J. Solution Chem. 12 (1983) 869-887.

118. S. Martinez, R. Garriga, P. Perez, M. Gracia, J. Chem. Eng. Data 48 (2003) 294-301.

119. R. Garriga, S. Martinez, P. Perez, M. Gracia, Fluid Phase Equilibr. 181 (2001) 203-214.

120. R. Garriga, F. Sanchez, P. Perez, M. Gracia, Ber. Bunsenges. Phys. Chem. 102 (1998) $14-24$.

121. R. Garriga, S. Martinez, P. Perez, M. Gracia, J. Chem. Thermodyn. 31 (1998) 117-127.

122. K. M. De Fina, T. L. Sharp, L. E. Roy, W. E. Acree, Jr., J. Chem. Eng. Data 44 (1999) 1262-1264.

123. G. C. Benson, Int/ DATA Ser., Sel. Data Mix. (1986) 244-246.

124. G. Geiseler, K. Suhnel, K. Quitzch, Z. Phys. Chem. (Leipzig) 254 (1973) 261-270.

125. F. Huyskens, H. Morissen, P. Huyskens, J. Mol. Struct. 441 (1998) 17-25.

126. Y. Miyano, J. Chem. Eng. Data 50 (2005) 211-215.

127. I. Brown, W. Fock, F. Smith, J. Chem. Thermodyn. 1 (1969) 273-291.

128. S. Warycha, Int. DATA Ser., Sel. Data Mix. (1994) 91-93.

129. S. Warycha, Int. DATA Ser., Sel. Data Mix. (1994) 115-117.

130. J. Pardo, A. M. Mainar, M. C. Lopez, F. Royo, J. S. Urieta, Fluid Phase Equilibr. 155 (1999) 127-137.

131. J. Pardo, M. C. Lopez, J. Santafe, F. M. Royo, J. S. Urieta, Fluid Phase Equilibr. 119 (1996) 165-173.

132. Y. Miyano, J. Chem. Thermodyn. 36 (2004) 865-869. 
133. B. Strothmann, O. Noll, k. Fischer, J. Gmehling, J. Chem. Eng. Data 44 (1999) 379-382.

134. L. Rohrschneider, Anal. Chem. 45 (1973) 1241-1247.

135. R. Garriga, S. Martinez, P. Perez, M. Gracia, J. Chem. Eng. Data 42 (2002) 322-328.

136. R. M. Villamanan, M. C. Martin, C. R. Chamorro, J. J. Segovia, J. Chem. Eng. Data 51 (2006) 148-152.

137. V. Rodriguez, J. Pardo, M. C. Lopez, F. Royo, J. S. Urieta, J. Chem. Eng. Data 38 (1993) $350-352$.

138. P. Oracz, Int. DATA Ser., Sel. Data Mix. (1989) 262-264.

139. R. Garriga, F. Sanchez, P. Perez, M. Gracia, Fluid Phase Equilibr. 130 (1997) 195-206.

140. P. Oracz, Int. DATA Ser., Sel. Data Mix. (1989) 253-255.

141. P. Oracz, Int. DATA Ser., Sel. Data Mix. (1989) 256-258.

142. P. Oracz, Int. DATA Ser., Sel. Data Mix. (1989) 259-261.

143. P. Oracz, Int. DATA Ser., Sel. Data Mix. (1989) 265-267.

144. S. Warycha, Int. DATA Ser., Sel. Data Mix. (1994) 94-96.

145. S. Warycha, Int. DATA Ser., Sel. Data Mix. (1994) 118-120.

146. S. G. Sayegh, G. A. Ratcliff, J. Chem. Eng. Data, 21 (1976) 71-74.

147. J. M. Rhodes, V. R. Bhethanabotla, S. W. Campbell, J. Chem. Eng. Data 42 (1997) 731734.

148. D. P. Barton, V. R. Bhethanabotla, S. W. Campbell, J. Chem. Eng. Data 41 (1995) 11381140.

149. I. M. Korenman, A. A. Gorokhov, Trudy po Khimii I Khimicheskoi Technolgii (1969) 111-115.

150. R. Garriga, S. Martinez, P. Perez, M. Gracia, Fluid Phase Equilibr. 149 (1998) 111-120. 
151. P. Oracz, Int. DATA Ser., Sel. Data Mix. (1989) 301-303.

152. P. Oracz. Int. DATA Ser., Sel. Data Mix. (1989) 232-234.

153. P. Oracz. Int. DATA Ser., Sel. Data Mix. (1989) 235-237.

154. P. Oracz. Int. DATA Ser., Sel. Data Mix. (1989) 238-240.

155. U. Domanska, J. A. Gonzalez, Fluid Phase Equilibr. 147 (1998) 251-270.

156. S. Bernatova, I. Wichterle, Fluid Phase Equilibr. 180 (2001) 235-245.

157. S. Fuangoo, M. Kersting, D. S. Viswanath, J. Chem. Eng. Data 44 (1999) 405-410.

158. G. C. Benson, Int. DATA Ser., Sel. Data Mix. (1985) 249-251.

159. M. H. Abraham, P. L. Grellier, J. Chem. Soc., Perkin Trans. 2 (1975) 1856-1862.

160. M. H. Abraham, P. L. Grellier, J. Mana, J. Chem. Thermodyn. 6 (1974) 1175-1179.

161. P. Oracz, Int. DATA Ser., Sel. Data Mix. (1989) 250-252.

162. P. Oracz, Int. DATA Ser., Sel. Data Mix. (1989) 247-249.

163. P. Oracz, Int. DATA Ser., Sel. Data Mix. (1989) 241-243.

164. P. Oracz, Int. DATA Ser., Sel. Data Mix. (1989) 295-297.

165. P. Oracz. Int. DATA Ser., Sel. Data Mix. (1989) 292-294.

166. P. Oracz. Int. DATA Ser., Sel. Data Mix. (1989) 298-300.

167. P. Oracz. Int. DATA Ser., Sel. Data Mix. (1989) 301-303.

168. P. Oracz. Int. DATA Ser., Sel. Data Mix. (1989) 304-306.

169. P. Oracz, Int. DATA Ser., Sel. Data Mix. (1989) 239-241.

170. S. Warycha, Int. DATA Ser., Sel. Data Mix. (1994) 97-99.

171. S. Warycha, Int. DATA Ser., Sel. Data Mix. (1994) 121-123. 
172. S. Warycha, Int. DATA Ser., Sel. Data Mix. (1994) 145-147.

173. P. Oracz. Int. DATA Ser., Sel. Data Mix. (1989) 236-238.

174. R. Garriga, S. Martinez, P. Perez, M. Gracia, J. Chem. Thermodyn. 33 (2001) 523-534.

175. C. Mintz, M. Clark, W. E. Acree, Jr., M. H. Abraham, J. Chem. Inf. Model. 47 (2007) $115-121$.

176. C. Mintz, K. Burton, T. Ladlie, M. Clark, W. E. Acree, Jr., M. H. Abraham, J. Mol. Liq. 144 (2009) 23-31. 
Table 1. Abraham model correlation equation coefficients for the transfer of solutes from water to the anhydrous (dry) alcohol solvents (log P correlation).

\begin{tabular}{|l|c|c|c|c|c|c|c|c|c|c|}
\hline Solvent & $\mathrm{c}$ & $\mathrm{e}$ & $\mathrm{s}$ & $\mathrm{a}$ & $\mathrm{b}$ & $\mathrm{v}$ & $\mathrm{N}$ & $\mathrm{SD}$ & $\mathrm{R}$ & $\mathrm{F}$ \\
\hline 2-Propanol & 0.099 & 0.344 & -1.049 & 0.406 & -3.827 & 4.033 & 148 & 0.159 & 0.994 & 4929 \\
\hline & $(0.027)$ & $(0.041)$ & $(0.059)$ & $(0.053)$ & $(0.067)$ & $(0.028)$ & & & & \\
\hline 2-Butanol & 0.127 & 0.253 & -0.976 & 0.158 & -3.882 & 4.114 & 97 & 0.129 & 0.994 & 3232 \\
\hline & $(0.029)$ & $(0.046)$ & $(0.060)$ & $(0.056)$ & $(0.079)$ & $(0.039)$ & & & & \\
\hline 2-Methyl-1-propanol & 0.188 & 0.354 & -1.127 & 0.016 & -3.568 & 3.986 & 104 & 0.154 & 0.986 & 1390 \\
\hline & $(0.040)$ & $(0.061)$ & $(0.072)$ & $(0.075)$ & $(0.117)$ & $(0.073)$ & & & & \\
\hline 2-Methyl-2-propanol & 0.211 & 0.171 & -0.947 & 0.331 & -4.085 & 4.109 & 113 & 0.164 & 0.998 & 9325 \\
\hline & $(0.032)$ & $(0.059)$ & $(0.081)$ & $(0.082)$ & $(0.104)$ & $(0.021)$ & & & & \\
\hline 3-Methyl-1-butanol & 0.073 & 0.360 & -1.273 & 0.090 & -3.770 & 4.273 & 62 & 0.099 & 0.996 & 2524 \\
\hline & $(0.043)$ & $(0.049)$ & $(0.071)$ & $(0.059)$ & $(0.108)$ & $(0.063)$ & & & & \\
\hline
\end{tabular}


Table 2. Abraham model correlation equation coefficients for the transfer of solutes from water to the anhydrous (dry) alcohol solvents (log K correlation).

\begin{tabular}{|l|c|c|c|c|c|c|c|c|c|c|}
\hline Solvent & $\mathrm{c}$ & $\mathrm{e}$ & $\mathrm{s}$ & $\mathrm{a}$ & $\mathrm{b}$ & $\mathrm{I}$ & $\mathrm{N}$ & $\mathrm{SD}$ & $\mathrm{R}$ & $\mathrm{F}$ \\
\hline 2-Propanol & -0.048 & -0.324 & 0.713 & 4.036 & 1.055 & 0.884 & 146 & 0.122 & 0.999 & 40021 \\
\hline & $(0.017)$ & $(0.035)$ & $(0.046)$ & $(0.041)$ & $(0.054)$ & $(0.006)$ & & & & \\
\hline 2-Butanol & -0.034 & -0.387 & 0.719 & 3.736 & 1.088 & 0.905 & 95 & 0.138 & 0.999 & 14696 \\
\hline & $(0.025)$ & $(0.054)$ & $(0.069)$ & $(0.059)$ & $(0.087)$ & $(0.011)$ & & & & \\
\hline 2-Methyl-1-propanol & -0.003 & -0.357 & 0.699 & 3.595 & 1.247 & 0.881 & 102 & 0.141 & 0.998 & 11302 \\
\hline & $(0.027)$ & $(0.068)$ & $(0.078)$ & $(0.073)$ & $(0.118)$ & $(0.017)$ & & & & \\
\hline 2-Methyl-2-propanol & 0.053 & -0.443 & 0.699 & 4.026 & 0.882 & 0.907 & 114 & 0.134 & 0.999 & 15412 \\
\hline & $(0.023)$ & $(0.049)$ & $(0.066)$ & $(0.065)$ & $(0.084)$ & $(0.005)$ & & & & \\
\hline 3-Methyl-1-butanol & -0.052 & -0.430 & 0.628 & 3.661 & 0.932 & 0.937 & 62 & 0.121 & 0.999 & 7861 \\
\hline & $(0.038)$ & $(0.069)$ & $(0.092)$ & $(0.073)$ & $(0.132)$ & $(0.019)$ & & & & \\
\hline & & & & & & & & & & \\
\hline 1-Propanol & -0.042 & -0.246 & 0.749 & 3.888 & 1.076 & 0.874 & & & & \\
\hline & $(0.019)$ & $(0.039)$ & $(0.052)$ & $(0.049)$ & $(0.056)$ & $(0.006)$ & & & & \\
\hline 1-Butanol & -0.004 & -0.285 & 0.768 & 3.705 & 0.879 & 0.890 & & & & \\
\hline & $(0.019)$ & $(0.042)$ & $(0.054)$ & $(0.055)$ & $(0.059)$ & $(0.007)$ & & & & \\
\hline
\end{tabular}




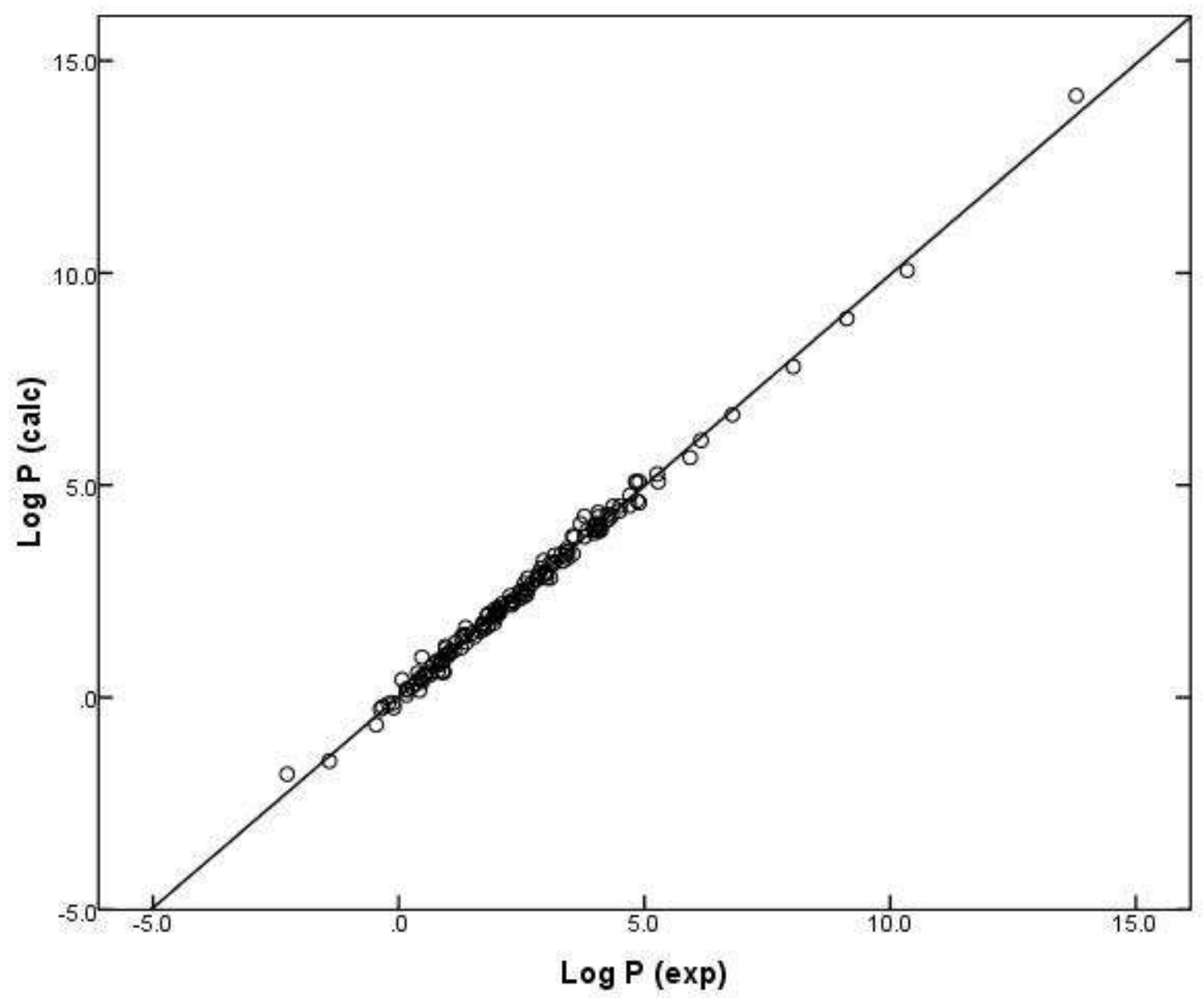

Figure 1. Comparison of the experimental $\log \mathrm{P}$ data for solutes dissolved in 2-propanol against calculated values based on Eqn. 8 . 


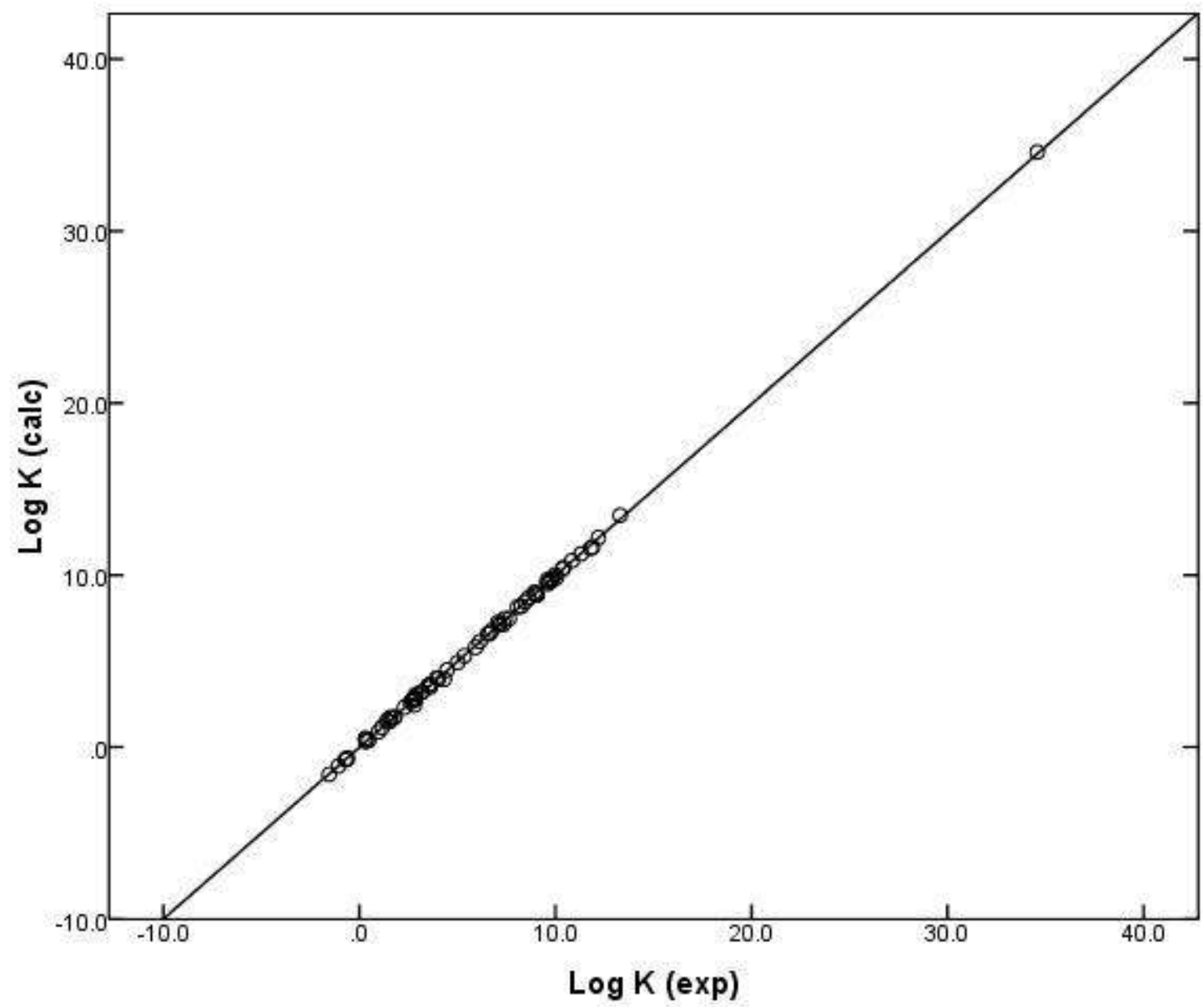

Figure 2. Comparison of the experimental $\log \mathrm{K}$ data for solutes dissolved in 2-propanol against calculated values based on Eqn. 9. 


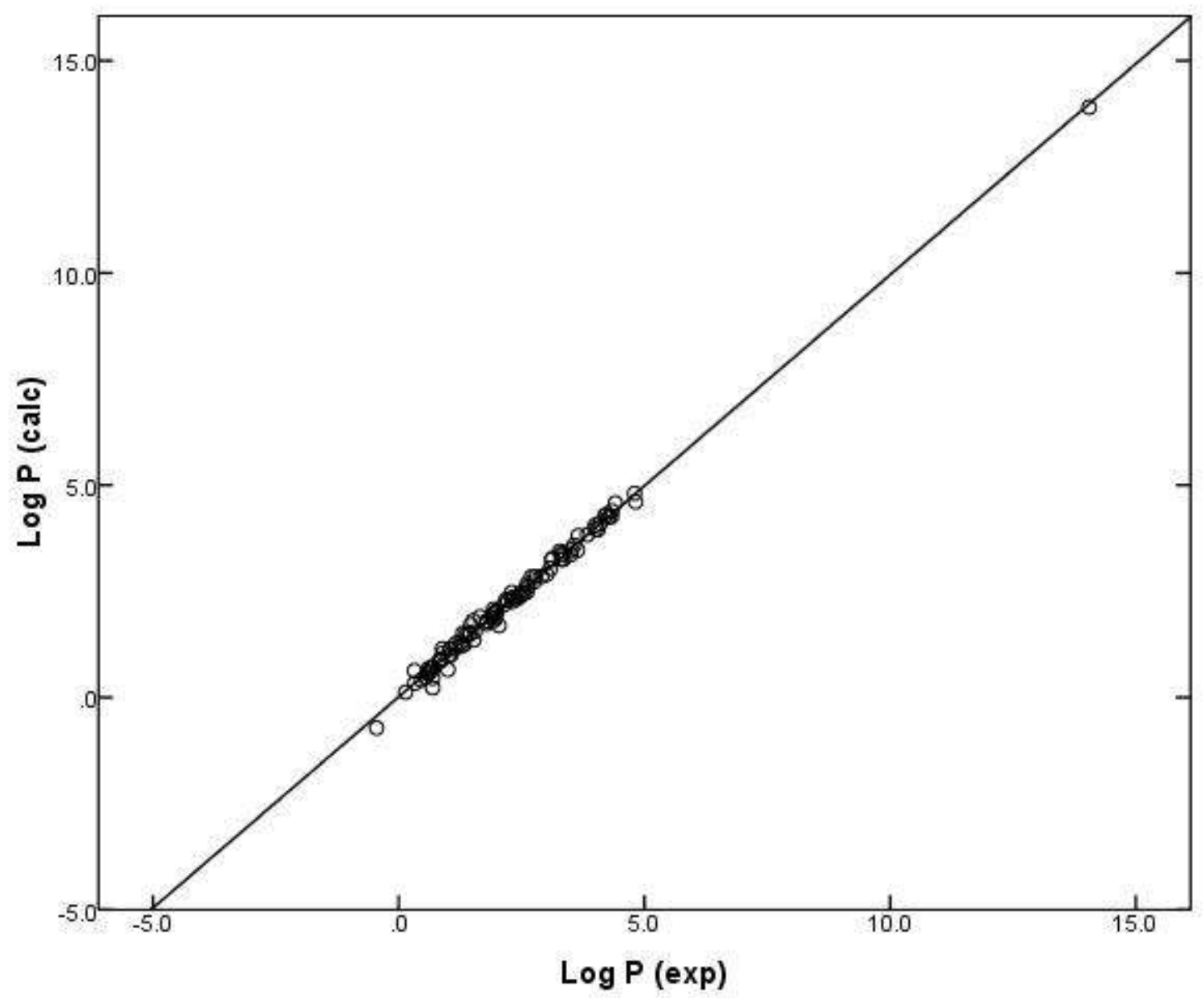

Figure 3. Comparison of the experimental $\log \mathrm{P}$ data for solutes dissolved in 2-butanol against calculated values based on Eqn. 12 . 


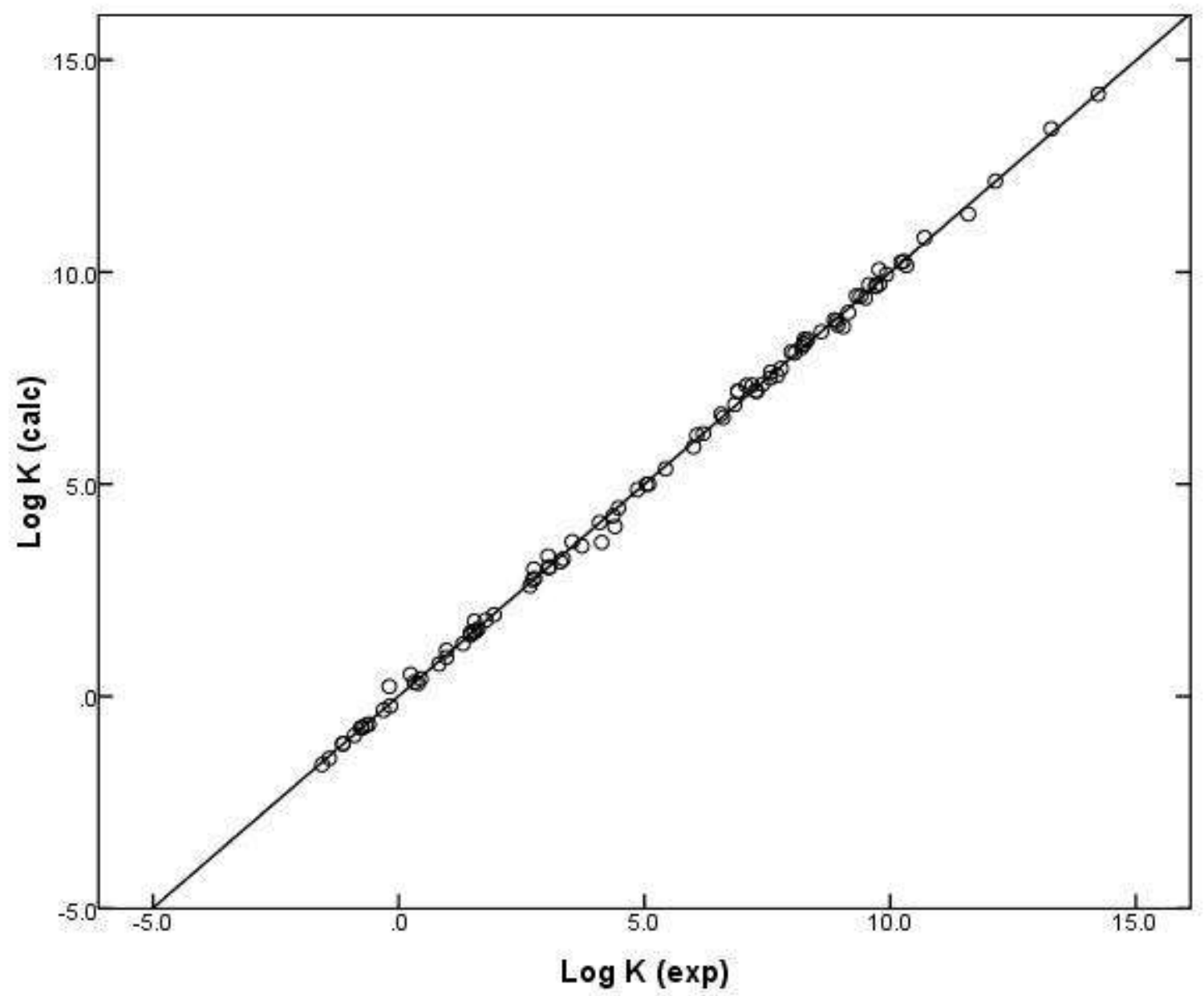

Figure 4. Comparison of the experimental $\log \mathrm{K}$ data for solutes dissolved in 2-butanol against calculated values based on Eqn. 13 . 